\title{
Assessing the Impact of Training on Employees' Performance in Commercial Banks in Urban Lahore
}

\author{
Anam Tahir* and Sumaira Sajjad**
}

\begin{abstract}
Training helps meet specific skill deficits in employees' performance. Successful organizations and managers realize the importance of human resources; trained human resources are key to maintaining a competitive advantage in today's constantly changing global environment. An efficiently implemented training program leads to better employee performance. This study aims to test for important training-related variables that significantly affect the performance of bank employees in urban Lahore. Using earlier studies on training and job performance, we identify key variables and analyze them through a questionnaire-based survey carried out among 75 local consumer bank employees at various managerial levels. It is evident from our findings that a proper needs assessment, the extent of a training program's effectiveness, investment by the host organization, and the provision of training programs all significantly affect employees' job performance. This study provides managers with an insight into important aspects of designing training programs to ensure higher employee productivity.
\end{abstract}

Keywords: Job performance, training, needs assessment.

JEL classification: M10, M53.

\section{Introduction}

Commercial banks undertake the business of risk. In recent years, globalization has led to a huge change in the financial sector worldwide. Although developing countries have not yet fully accommodated all the changes in the financial world, they have begun to cater for recent developments in the money and capital markets. Financial liberalization is an important concept in this regard. This study attempts to analyze urban Lahore's foreign and local commercial banks on the basis of their human resource activities, which play an important role in the development of the economy's banking sector.

\footnotetext{
* Anam Tahir is a research and teaching fellow at the Lahore School of Economics, and can be contacted at anamtahir788@gmail.com.

** Sumaira Sajjad is a teaching fellow at the Lahore School of Economics.
} 
Financial institutions today face huge organizational responsibilities in order to cope in a competitive environment, where they must ensure that they sustain their own existence, and maintain and improve the quality of their services over time. The core activities of all financial institutions are the same and they compete largely on the basis of their human resource activities. Pakistan's banking sector has broadened in the past few years with the entry of many new foreign financial institutions, especially after 9/11. Foreign banks have found a number of opportunities in the country, and the inflow of foreign aid has been important in this regard.

This study aims to analyze the key training factors that lead to improved job performance among employees. Job performance can be enhanced by multiple factors including increased levels of pay or by nonmonetary incentives such as advanced education, among others.

Training is the process of providing employees with specific skills or helping them correct deficiencies in their performance. Development, on the other hand, is the effort to provide employees with abilities the organization will need in the future (Reed \& Vakola, 2006). They are usually carried out when employees have a skill deficit or when an organization brings about a change in its system and employees are required to learn new skills (Roberson, Culik, \& Pepper, 2001). In the banking industry, training programs may be conducted not only to meet skill deficits or to bring about systemic change, they can also be used as an effective tool by the organization to implement new policies issued by higher authorities or by the central bank.

Successful organizations and managers realize the importance of human resources-trained human resources are key to maintaining a competitive advantage (Schonewille, 2001). Such organizations consider employee training an investment rather than an expense. Every organization wants its employees to be up to date and have the best skills, so that their training can keep pace with the organization's changing environment. Consistent quality of product and services is critical to an organization's survival in a competitive environment. It is, therefore, vital for an organization to design cost-effective training programs for its employees from time to time.

Training and motivation are interlinked concepts (Mann, 1996). Whatever the process adopted, the ultimate aim is to enhance the technical and personal skills of an individual employee while also developing his/her 
management skills. The appropriate amount of opportune training and development leads to increased employee productivity, knowledge, and loyalty to the organization (organizational commitment) and contributes to its betterment (Analoui, 1994). An effective needs assessment along with an efficiently launched training program can help refine the organization's objectives, putting it in a better position to analyze its employees' capabilities and direct them accordingly (Tziner, Fisher, Senior, \& Weisberg, 2007).

\subsection{Theoretical Framework}

Figure 1 illustrates factors identified in the literature that contribute to better job performance.

Figure 1: Factors contributing to job performance

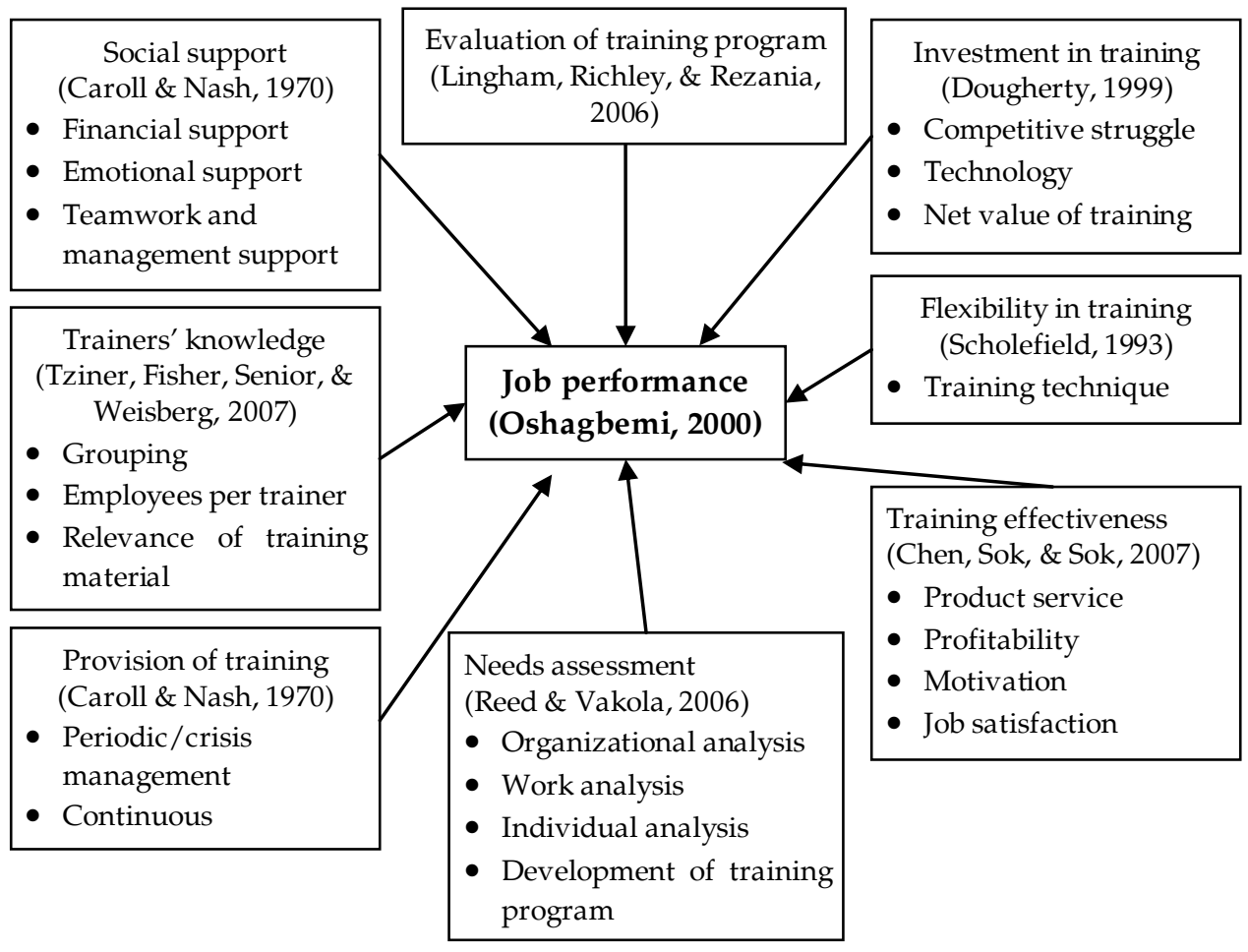

\subsection{Study Objective}

Our objective is to test the proposition that training-related variables-for example, effective needs assessment, training program evaluation, investment in training, educational needs, flexibility in training, provision of training, incentives, social support, transfer of knowledge, 
leadership qualities, training opportunity, trainer's knowledge, training effectiveness, know-your-customer policy, negotiation skills, total quality management, behavioral skills, and emotional intelligence-have a significant or insignificant impact on employees' job performance.

\section{Review of the Literature}

Training is defined as the systematic acquisition of skills, rules, concepts, or attitudes that result in improved job performance (Goldstein, 1993). The closer a training program is to organizational goals, the more effective it is considered. Bozionelos and Lusher (2002), Stevens (1996), Stumpf (1998), and Arnone (1998) define training as the process of creating a design that meets an organization's needs, targets its participants, and provides a feedback system to redesign and adjust further iterations of the program based on organizational and participant perspectives and needs. This is a broader definition since it accounts for the entire training process, specifically the four-phase approach modeled by Lingham, Richley, and Rezania (2006). This includes: (i) designing the training initial program, (ii) launching and evaluating the initial program, (iii) designing quantitative measures based on feedback from Phase II, and (iv) ongoing training and evaluation.

McClelland (1994) argues that content is more important than applicability in any training program, suggesting that training evaluation is the most ignored part of the process. The study identifies budgetary and other constraints that may cause trainers and program designers to employ standardized, commercially available evaluation instruments that have many disadvantages. Among these are that standardized instruments are neither comprehensive nor focused on areas of critical content that would be either necessary or desirable.

Evaluation is related to efficiency, effectiveness, and impact (Rossi \& Freeman, 1989). McCoy and Hargie (2001) argue that no one model of evaluation is complete and suited to all situations; each has its strengths and weaknesses. The key aim of evaluating a training program is to analyze the extent to which its objectives match the organization's goals and objectives. Once the program has been evaluated thoroughly, the key factors that contribute to its success or failure can be identified as its positive and negative features. The organization will then able to assess how successful its investment in that program has been, and what else it needs to add to improve it according to the needs of individual employees (Philips, 1996). By gaining organizational satisfaction among individual employees, it will be easier for the organization to retain them. 
Pfeffer (2000) shows that training can be a source of competitive advantage in numerous industries. Given that the world market structure is competitive, continuous improvement is imperative for organizations. Training and learning are the key organizational ongoing processes that contribute to growth. White and Mackenzie-Davey (2003) support this argument, and indicate that training has become part of organizational learning and change, employee evaluation, and career development.

Training effectiveness can be analyzed through various factors, including product service, institution profitability, work motivation, work efficiency, individuals' ability and knowledge, smaller wastage of resources, and level of job satisfaction (Drucker, 1995). An effective training program leads to an improvement in the quality of services.

In the current "global environment," with employees being tasked to take on new challenges and responsibilities, it has become increasingly important to train managers as leaders (Black \& Gregersen, 2000). At the center of this environment is the need to help individuals learn in order to meet both organizational targets and personal objectives. The implications for the training and development sector has therefore taken on a new significance with over one third of the educational budget in Fortune 500 companies being spent on employee development at the middle and upper levels (Klein, Astrachan, \& Kossek, 1996).

An educated and well-trained work force is considered essential to maintaining a business firm's competitive advantage in a global economy. Training can prove a powerful agent in facilitating a firm's expansion and developing its capabilities, thus enhancing profitability (Cosh, Duncan, \& Hughes, 1998).

\section{Research Methodology}

Since this is a primary study, data was collected using a questionnaire designed to ensure high-quality results while minimizing the chances of bias. The survey was conducted at various managerial levels at banks in urban Lahore.

\subsection{Sample}

Our study population consisted of employees of urban banks in Lahore who had (i) previously undergone a training program and (ii) were familiar with the outcomes of that program. Moreover, of the urban banks considered, we shortlisted those that could be surveyed easily. The areas 
under consideration included the Defence Housing Authority, the Lahore Cantonment, Gulberg, and the Upper Mall. The study's reference period is April 2008.

Although the actual sample size was 100, our study is based on data generated from 75 questionnaires. The target sample size could not be achieved due to insufficient time and because the questionnaire was too long, which discouraged most respondents from completing it.

\subsection{Hypothesis}

We test the following hypotheses:

- Training effectiveness has a significant/insignificant impact on job performance.

- Investment in training has a significant/insignificant impact on job performance.

- Effective needs assessment has a significant/insignificant impact on job performance.

- Provision of training has a significant/insignificant impact on job performance.

- Educational needs have a significant/insignificant impact on job performance.

- Evaluation of training has a significant/insignificant impact on job performance.

- Flexibility of training has a significant/insignificant impact on job performance.

- Incentives have a significant/insignificant impact on job performance.

- A know-your-customer policy has a significant/insignificant impact on job performance.

- Leadership qualities have a significant/insignificant impact on job performance.

- Negotiation skills have a significant/insignificant impact on job performance.

- Social support has a significant/insignificant impact on job performance.

- Total quality management has a significant/insignificant impact on job performance. 
- Trainer's knowledge has a significant/insignificant impact on job performance.

- Training opportunity has a significant/insignificant impact on job performance.

- Training effectiveness has a significant/insignificant impact on job performance.

- Transfer of knowledge has a significant/insignificant impact on job performance.

\subsection{Data Analysis}

The data was analyzed using stat graphics software. Multiple regression models were established based on the data obtained through the questionnaire survey. An initial model was developed using all the independent variables, but many insignificant variables were dropped to obtain a final significant model. All the hypotheses were tested at a 0.05 level of significance. P-values were used to test for the significance of variables.

The general form of the multiple regression equation is:

$$
Y=\alpha+\beta_{1} X_{1}+\beta_{2} X_{2}+\beta_{3} X_{3}+\ldots+\beta_{n} X_{n}
$$

where $X_{1}$ is evaluation of training program, $X_{2}$ is investment in training, $X_{3}$ is flexibility in training, $X_{4}$ is provision of training, $X_{5}$ is needs assessment, $X_{6}$ is training effectiveness, $X_{7}$ is social support, and $X_{8}$ is trainer's knowledge.

\subsection{Theoretical Justification of Variables}

A training needs assessment is considered to have a positive relationship with employee job performance. An effective needs assessment followed by the launch and evaluation of a training program is also considered to have a positive relationship with job performance, and implies that the trainer has been able to analyze employees' strengths and weaknesses. Needs assessments are carried out at three levels: (i) organizational, (ii) work, and (iii) individual.

Investment in training is also an important variable-the more a bank invests in its training programs, the better it can train its employees to handle potential problems and policy changes by the central bank. More efficient employee performance will thus enhance the bank's problem solving ability. Investment in training is thus considered to have a positive relationship with job performance. 
Training techniques are important components of the training process. Some techniques are considered more effective than others, and generally require an employee's practical participation in a real-life situation rather than theoretical teaching, which may not be as suited to all circumstances.

Provision of training is an important variable-the more chances an employee is given to undertake training programs, the better his/her job performance will be. Training provision is generally of two types: (i) needbased training, which is geared toward crisis management; and (ii) continuous training that goes hand in hand with an employee's normal work routine. Institutions such as banks need to ensure the provision of both types of training since both can be used to enhance employees' skills and efficiency.

Evaluation of the training process is important because it helps the organization assess how far the training matched its needs and whether it has improved its employees' performance and skills. Better, more effective evaluations enable the organization to restructure its policies as required by identifying the program's weaknesses and helping them improve employees' performance more efficiently.

The training process can also be used to enhance employees' educational skills in the short and long term. Our study, however, shows that training caters for short-term educational needs rather than long-term needs. This implies that, while training can help address short-term skill deficiencies, in the long term, employees' education levels need to be improved in order to improve their job performance. The study is used to give a clearer picture of this argument.

Monetary and nonmonetary incentives along with social support from peer groups and supervisors encourage employees to undertake training programs. The training, in turn, helps employees improve their job performance.

Trainers' knowledge is an important factor contributing to employees' job performance. A trainer's choice of the type of grouping is also an important factor. Heterogeneous groups of trainees as opposed to homogeneous groups allow for greater improvement. This depends only on how the trainer perceives the training process, and is expected to have a positive relationship with employees' job performance. 
The transfer of knowledge comprises (i) the transfer of knowledge from trainer to trainees, and (ii) from trainees to the workplace. The more effective the transfer process, the better employees' performance will be.

\section{Statistical Analyses}

\subsection{Descriptive Statistics}

The fieldwork for this study was conducted in natural settings. Almost 85 percent of the total sample population comprised males. All the bank employees surveyed were aged between 24 to 35 years, and the duration of their work experience varied from one to five years, implying that all the data was collected from the same group of people. An important point to note here is that the information above is based on only 60 percent of the entire sample since almost 40 percent of the respondents were reluctant to provide personal information.

\subsection{Tests of Significance of Regression, Parameters, and Regression Equation for Initial Model}

The initial model incorporates 15 independent and one dependant variable, i.e., job performance. Based on the data collected, we have developed the model shown in Table 1 below.

Table 1: Multiple regression analysis - initial model

\begin{tabular}{|c|c|c|c|c|c|c|c|}
\hline \multicolumn{2}{|l|}{ Parameter } & Estimate & \multicolumn{2}{|c|}{ Standard error } & \multicolumn{2}{|c|}{ t-statistic } & p-value \\
\hline \multicolumn{2}{|c|}{ Constant } & -0.14973 & \multicolumn{2}{|c|}{1.068610} & \multicolumn{2}{|c|}{-0.140120} & 0.8898 \\
\hline \multicolumn{2}{|c|}{ Training effectiveness } & 0.19800 & \multicolumn{2}{|c|}{0.146993} & \multicolumn{2}{|c|}{1.346980} & 0.1911 \\
\hline \multicolumn{2}{|c|}{ Evaluation of training } & 0.00665 & \multicolumn{2}{|c|}{0.126097} & \multicolumn{2}{|c|}{0.052715} & 0.9584 \\
\hline \multicolumn{2}{|c|}{ Flexibility in training } & 0.06691 & \multicolumn{2}{|c|}{0.167701} & \multicolumn{2}{|c|}{0.398999} & 0.6936 \\
\hline \multicolumn{2}{|c|}{ Investment in training } & 0.10967 & \multicolumn{2}{|c|}{0.116683} & \multicolumn{2}{|c|}{0.939920} & 0.3570 \\
\hline \multicolumn{2}{|c|}{ Needs assessment } & 0.24211 & \multicolumn{2}{|c|}{0.139524} & \multicolumn{2}{|c|}{1.735270} & 0.0961 \\
\hline \multicolumn{2}{|c|}{ Provision of training } & 0.11529 & \multicolumn{2}{|c|}{0.118943} & \multicolumn{2}{|c|}{0.969293} & 0.3425 \\
\hline \multicolumn{2}{|c|}{ Social support } & -0.14437 & \multicolumn{2}{|c|}{0.124032} & \multicolumn{2}{|c|}{-1.163940} & 0.2564 \\
\hline \multicolumn{2}{|c|}{ Trainers' knowledge } & 0.21655 & 0.15 & 7118 & 1.37 & 3290 & 0.1814 \\
\hline & & Analys & is of var & & & & \\
\hline Source & Sum of & ares & $\begin{array}{l}\text { ees of } \\
\text { dom }\end{array}$ & Mean & uare & F-ratio & p-value \\
\hline Model & 4.91 & & 8 & 0.307 & & 2.96 & 0.0088 \\
\hline Residual & 2.38 & & 23 & 0.103 & & - & - \\
\hline Total (corr.) & 7.29 & & 39 & - & & - & - \\
\hline
\end{tabular}




\begin{tabular}{ll}
\hline R-squared & 67.3027 percent \\
R-squared (adjusted for DF) & 44.5567 percent \\
Standard error of est. & 0.322141 \\
Mean absolute error & 0.195561 \\
Durbin-Watson statistic & 2.502110 \\
\hline
\end{tabular}

Source: Authors' calculations.

The results of this regression were not sufficiently reliable or consistent with our expectations based on the literature review. We therefore developed a final model by running the regressions a second time, but dropping a number of insignificant variables.

\subsection{Final Model}

All the variables that were insignificant and whose signs were not consistent with our expectations were dropped. The final regression equation is thus as follows:

Job performance $=0.316977^{*}$ effectiveness of training + $0.196026^{*}$ investment in training $+0.287705^{*}$ needs assessment + $0.22946^{*}$ provision of training

Table 2: Final model

\begin{tabular}{|c|c|c|c|c|c|c|c|}
\hline \multicolumn{2}{|l|}{ Parameter } & Estimate & \multicolumn{2}{|c|}{ Standard error } & \multicolumn{2}{|c|}{ t-statistic } & p-value \\
\hline \multicolumn{2}{|c|}{ Training effectiveness } & 0.316977 & \multicolumn{2}{|c|}{0.095599} & \multicolumn{2}{|c|}{$3.31570^{*}$} & 0.0021 \\
\hline \multicolumn{2}{|c|}{ Investment in training } & 0.196026 & \multicolumn{2}{|c|}{0.083303} & \multicolumn{2}{|c|}{$2.35317^{*}$} & 0.0242 \\
\hline \multicolumn{2}{|c|}{ Needs assessment } & 0.287705 & \multicolumn{2}{|c|}{0.094842} & \multicolumn{2}{|c|}{$3.03351^{*}$} & 0.0045 \\
\hline \multicolumn{2}{|c|}{ Provision of training } & 0.229460 & \multicolumn{2}{|c|}{0.078897} & \multicolumn{2}{|c|}{$2.90835^{*}$} & 0.0062 \\
\hline \multicolumn{8}{|c|}{ Analysis of variance } \\
\hline \multicolumn{8}{|c|}{ Degrees of } \\
\hline Model & 700. & & 4 & 175 & & $1,708.2$ & 0.0000 \\
\hline Residual & 3.68 & & 36 & 0.10 & & - & - \\
\hline Total (corr.) & 703 & & 40 & - & & - & - \\
\hline
\end{tabular}




\begin{tabular}{ll}
\hline R-squared & 99.4759 percent \\
R-squared (adjusted for DF) & 99.4322 percent \\
Standard error of est. & 0.320073 \\
Mean absolute error & 0.240137 \\
Durbin-Watson statistic & 2.243710 \\
\hline
\end{tabular}

Source: Authors' calculations.

The model's p-value as shown in the analysis of variance is 0.0000 , i.e., less than 0.01 , which implies that a statistically significant relationship exists for the variables under consideration at a 99 percent confidence interval. If we analyze the individual $\mathrm{p}$-values of all the variables included in the model, we find that they are all significant since their p-values are less than 0.01, except for that of investment in training, which is greater than 0.01 but less than 0.05 , which still makes it statistically significant. A pvalue of 0.024 is not so large that it should allow us to ignore as important a variable as investment in training, which is of great significance in the banking sector.

The R-squared statistic indicates that the fitted model explains almost 99.5 percent of the variability in job performance. All the other variables were dropped because they appeared to be insignificant in this study, probably because of the sample size.

The signs and magnitudes of the variables given above are in line with the expected results. Training effectiveness has a significant impact on employees' job performance. It has a positive relationship with the job performance variable, implying that the more effective a training program and the more consistently a trainer succeeds in training an organization's employees, the better their job performance will be.

Investment in training is also an important variable as evident from our findings. The more banks invest in their training programs, the better they can train their employees to handle potential problems and policy changes. The more efficient the performance of their employees, the better the banks' problem solving abilities will be. This justifies the positive significant relationship between investment in training and employees' job performance.

Training needs assessment was expected to have a positive relationship with employees' job performance. An effective needs assessment followed by the launch and evaluation of a training program 
enhances job performance, and implies that the trainer has been able to analyze employees' strengths and weaknesses. Our results are as expected, as evident from the final model.

Provision of training also has a significant positive relationship with job performance, implying that managers can only expect better performance from their employees if they are willing to provide the latter with the necessary skills through training programs.

\section{Conclusion}

As we have shown, training addresses specific skill deficits in the performance of employees. Successful organizations that wish to maintain a competitive advantage in the global environment employ training as a tool to keep pace with the changing organizational environment. The efficient implementation of training programs leads to better employee performance.

This study has tested the significance of training-related variables that affect the performance of bank employees in urban Lahore. Using earlier studies on training and job performance, we have identified a number of key variables that were further analyzed through a questionnaire survey carried out among 75 local consumer bank employees at various managerial levels. We developed two competing econometric models of job performance-using alternative specifications of variables and econometric approaches - and consolidated these to determine the relative strengths of the independent variables.

The initial model included variables such as effective needs assessment, evaluation of training program, investment in training, flexibility in training, provision of training, social support, transfer of knowledge, leadership qualities, trainer's knowledge, and training effectiveness. Our findings based on the final model showed, however, that proper needs assessment, effectiveness of training program, investment in training, and provision of training all significantly affect employees' job performance. The study's results provide managers an insight into important aspects of designing training programs to ensure an increase in the productivity of employees. 


\section{References}

Analoui, F. (1994). Training and development: The role of trainers. Journal of Management Development, 13(9), 61-72.

Arnone, M. (1998). Corporate universities: A viewpoint on the challenges and best practices. Career Development International, 3(5), 199-205.

Black, S. J., \& Gregersen, H. B. (2000). High impact training: Forging leaders for the global frontier. Human Resource Management, 39(2/3), 173-185.

Bozionelos, N., \& Lusher, S. (2002). Team leaders' development: Findings from a case study. Career Development International, 7(1), 47-51.

Caroll, S. J., \& Nash, A. N. (1970). Some personal and situational correlates of reactions to management development training: Reply. The Academy of Management Journal, 13(4), 453-457.

Chen C.-Y., Sok P., \& Sok, K. (2007). Exploring potential factors leading to effective training: An exclusive study on commercial banks in Cambodia. Journal of Management Development, 26(9), 843-856.

Cosh, A., Duncan, J., \& Hughes, A. (1998). Investing in training and small firm growth and survival: An empirical analysis for the UK 1987-1997 (DFEE Research Report No. RR36). London, UK: HMSO.

Dougherty, C., \& Tan, J.-P. (1999). Financing training: Issues and options. Journal of European Industrial Training, 23(9), 416-436.

Drucker, P. F. (1995). Managing in a time of great change. New York, NY: Truman Talley.

Elangovan, A. R., \& Karakowsky, L. K. (1999). The role of trainee and environmental factors in transfer of training: An exploratory framework. Leadership and Organization Development Journal, 20(5), 268-276.

Goldstein, I. L. (1993). Training in organization: Needs assessment, development and evaluation (3rd ed.). California: Brooks/Cole Publishing Co. 
Karia, N., \& Asaari, M. H. A. H. (2006). The effects of total quality management practices on employees' work-related attitudes. The TQM Magazine, 18(1), 30-43.

Klein, E. B., Astrachan, J. H., \& Kossek, E. E. (1996). Leadership education: The impact of managerial level and gender on learning. Journal of Managerial Psychology, 11(2), 31-40.

Lingham, T., Richley, B., \& Rezania, D. (2006). An evaluation system for training programs: A case study using a four-phase approach. Career Development International, 11(4), 334-351.

Mann, S. (1996). What should training evaluations evaluate? Journal of European Industrial Training, 20(9), 14-20.

McClelland, S. (1994). A model for designing objective-oriented training evaluations. Industrial and Commercial Training, 26(1), 3-9.

McCoy, M., \& Hargie, O. D. W. (2001). Evaluating evaluation: Implications for assessing quality. International Journal of Health Care Quality Assurance, 14(7), 317-327.

Oshagbemi, T. (2000). Is length of service related to the level of job satisfaction? International Journal of Social Economics, 27(3), 213-226.

Pfeffer, J. (2000). Seven practices of successful organizations. In W. L. French, C. H. Bell, \& R. A. Zawacki (Eds.), Organizational development and transformation: Managing effective change (pp. 494514) (5th ed.). Singapore: McGraw-Hill.

Phillips, J. J. (1996). ROI: The search for best practices. Training $\mathcal{E}$ Development, 50(2), 42-47.

Reed, J., \& Vakola, M. (2006). What role can a training needs analysis play in organizational change? Journal of Organizational Change Management, 19(3), 393-407.

Roberson, L., Culik, C. T., \& Pepper, M. B. (2001). Designing effective diversity training: Influence of group composition and trainee experience. Journal of Organizational Behavior, 22(8), 871-885.

Rossi, P. H. \& Freeman, H. E. (1989). Evaluation: A systematic approach (4th ed.). Newbury Park, CA: Sage. 
Scholefield, M. (1993). Implementing training and development standards: The background. Industrial and Commercial Training, 25(10), 250-259.

Schonewille, M. (2001). Does training generally work? Explaining labor productivity effects from schooling and training. International Journal of Manpower, 22(1/2), 158-173.

Stevens, P. (1996). What works and what does not in career development programmes. Career Development International, 1(1), 11-18.

Stumpf, S. A. (1998). Corporate universities of the future. Career Development International, 3(5), 206-211.

Tepper, B. J., Duffy, M. K., Hoobler, J. M., \& Ensley, M. D. (2004). Moderators of the relationship between coworkers' organizational citizenship behavior and fellow employees' attitudes. Journal of Applied Psychology, 89, 455-465.

Tziner, A., Fisher, M., Senior, T., \& Weisberg, J. (2007). Effect of trainee characteristics on training effectiveness. International Journal of Selection and Assessment, 15(2), 167-174.

White, M., \& Mackenzie-Davey, K. (2003). Feeling valued at work? A qualitative study of corporate training consultants. Career Development International, 8(5), 228-234. 